\title{
Educação e cultura: Brasil e Japão
}

\author{
Sumiko Nishitani Ikeda*
}

* Professora da Pós-Graduação em Linguística Aplicada e Estudos da Linguagem (Lael) da Pontifícia Universidade Católica de São Paulo (PUC-SP), SP, Brasil.sumiko@uol.com.br.

KISHIMOT0, Tizuko M.; DEMARTINI, Zeila de B. Educação e cultura: Brasil e Japão. São Paulo: EDUSP, 2012. 242 p.

A leitura do livro Educação e cultura: Brasil e Japão (Kishimoto; Demartini, 2012), uma coletânea que traz várias pesquisas de estudiosos da imigração japonesa no Brasil, fez-me pensar que deveria compartilhar essa rica experiência com outras pessoas. Assim, preparei-me para escrever uma resenha, tendo em mente um texto de cunho acadêmico, impessoal, de tom comedido. Porém, durante o exame do livro, a cada página que virava, teve início em mim uma série de recordações longínquas, mas ainda muito vivas em minha memória. Eis por quê: nasci em 1938 e vivenciei a maior parte do que relata o livro e, mais ainda, permaneci por seis anos (1992-1998) no Japão, lecionando e pesquisando, como kyooju (professora titular), na Osaka University of Foreign Studies; na Kyoto University of Foreign Studies; e na Ko- kuritsu Kokugo Kenkyujoo, em Tóquio, quando atuei, também, em ONGs de ajuda ao decasségui. Era como se a vida me proporcionasse presenciar os primórdios da imigração japonesa no Brasil e a atual situação, agora, no Japão.

Educação e Cultura: Brasil e Japão está dividido em cinco partes: Imigração, Estado e Escolarização; Identidade e Valores; Infância, Educação e Cultura; Ensino da Língua Japonesa; Movimento Decasségui e Educação e resgata a história da imigração japonesa no Brasil, iniciada em 1908, em razão da necessidade de força de trabalho para as lavouras de café, e interrompida em 1941, na sua primeira etapa; foi retomada em 1952, seguindo até 1979. Em 1977, só o estado de São Paulo concentrava 727.605 pessoas de origem japonesa e seus descendentes.

Como os imigrantes japoneses - por questões raciais - não mais puderam emigrar para a América Central e para a América do Norte, seu destino passou a 
ser o Brasil, pois o contexto brasileiro no início do século XX era propício a essa imigração, segundo relata Kobayashi, no capítulo "Asobi Mashou: a cultura lúdica dos descendentes de japoneses". A abolição da escravatura no Brasil (1988), continua a autora, a expansão das lavouras de café, a necessidade de mais trabalhadores e um possível desenvolvimento nas relações comerciais com o Japão foram os principais fatores brasileiros que contribuíram para a vinda desses imigrantes ao nosso país.

Os dados das pesquisas de que resultou o livro foram, em sua maioria, levantados e coletados tanto em fontes bibliográficas, quanto em entrevistas, na tentativa de reconstruir as conexões entre o passado e o presente, por meio de um trabalho com relatos orais sobre experiências de pessoas comuns que, vindas do Japão, chegaram a São Paulo e ao Paraná nas décadas de 1920 e 1930; e de famílias que chegaram no Pós-Guerra. Podemos, assim, compreender a complexidade das situações enfrentadas pelos japoneses no Brasil.

A leitura de Educação e Cultura: Brasil e Japão proporciona a pessoas que, como eu, sofreram a discriminação após a derrota do Japão na II Guerra e a consequente impossibilidade de retorno ao país natal, a compreensão desta situação com riqueza de detalhes: o Brasil precisando da força de trabalho dos imigrantes na lavoura; estes tentando manter sua língua, sua tradição, seus valores (o shushin, a educação moral e cívica; o bushido, código de conduta do samurai) em terra estrangeira, com todas as implicações que esse processo acarreta, como bem explicam os capítulos do livro. Historicamente, revela Demartini, em “Japoneses em São Paulo: desafios da educação na nova terra”, os japoneses foram considerados os imigrantes mais indesejáveis e inassimiláveis, pois eram amarelos, não europeus e não católicos. Éramos o "perigo amarelo", fato destacado nos debates da Constituinte de 1934, colocando em questão a continuidade da imigração japonesa para o Brasil, época em que a maioria dos japoneses teve seus bens sequestrados pelo governo brasileiro. Assim informa o capítulo "A nacionalização do ensino e os japoneses em São Paulo", de autoria de Shibata.

Eu era criança, na época, e lembro-me de que tinha muito medo, sentia-me diferente, enfrentando culturas totalmente diversas, além de duas línguas distintas, uma em casa e outra na escola, em que a parte japonesa, devido às circunstâncias, não levava vantagem. Custou-me muito tempo e muitas sessões de ajuda para, aos poucos, aceitar a diferença, que envolvia desde as roupas 
íntimas, a alimentação, o comportamento na sala de aula ou nas brincadeiras com a meninada da vizinhança, em que frequentemente me sentia discriminada.

O livro mostra, então, que essa discriminação não se resumia simplesmente a uma questão pessoal, mas decorria de profundas diferenças culturais e, na obra aqui apresentada, cada capítulo mostra como isso acontecia: o alto grau de escolaridade do imigrante japonês, que o fez tentar suprir a educação dos filhos e promover a cooperação entre os membros e a comunicação entre os núcleos coloniais existentes: Rio Grande do Sul, Santa Catarina, Paraná e São Paulo, segundo Shibata, com isso levantando suspeitas por parte das autoridades brasileiras; o Yamato damachii, que designava um corpo de valores éticos e morais, práticas e representações, que não se esgotavam em seu caráter militarista, mas se expressavam em toda a extensão da vida cotidiana. Nesse sentido, "vencer na vida” não significa necessariamente o acúmulo de riquezas, mas é interpretado como a manutenção de uma conduta moral reta; e significa, até, o papel da mãe japonesa, que age com aparente indiferença na educação dos filhos, sem as cobranças comuns no Ocidente.

Ocada, em "Valores presentes na identidade ética nipobrasileira”, revela que os dois primeiros fatos - a educação e o damachii - fizeram os imigrantes, enganados por promessas mirabolantes de ganho financeiro fácil e lançados no trabalho braçal a que não estavam acostumados, preocupar-se com a educação de seus filhos. A necessidade de construir escolas para esse fim foi impositiva, já que o governo brasileiro acabou deixando aos imigrantes a resolução dessa questão, como diz Capelo, em “Educação e escolarização japonesa nas colônias rurais". Assim, já era muito grande o número de escolas japonesas existentes no estado de São Paulo na década de 1930, em que as aulas eram ministradas nas duas línguas. Hoje, sabe-se que um dos fatores que permitiram a rápida integração dos japoneses em São Paulo foi o grande investimento realizado pelas famílias na educação dos filhos. Camacho, por exemplo, em "Valores culturais japoneses presentes na educação dos nipo-brasileiros”, estuda as relações entre a cultura japonesa e a educação dos imigrantes japoneses e seus descendentes, para compreender os valores culturais que influem no desempenho escolar positivo dos nipo-brasileiros.

Mas, naquele tempo, diante do fortalecimento de grupos imigrantes, o governo implantou políticas nacionalistas que visavam a controlar os imigrantes e evitar que constituíssem os considerados "perigosos enquistamentos ét- 
nicos" (Demartini, 1979)ํ․․ As medidas tomadas pelo presidente Getúlio Vargas para conseguir uma rápida integração dos estrangeiros à sociedade brasileira prejudicaram o grupo japonês. Da minha parte, agora posso entender o motivo da proibição do estudo da língua japonesa e por que precisávamos camuflar os livros escolares em sacolas de feira e assistir a aulas dadas nem sempre por professores categorizados, em obscuras garagens das casas.

Quanto ao terceiro fato, referente à mãe japonesa, lembro-me de meu filho, nascido em 1980, perguntar-me, aos dez anos de idade, se eu era "normal", já que minhas atitudes eram diferentes daquelas das mães que ele conhecia. Ou seja, mesmo depois de tanto tempo, parece que o imigrante mantinha ainda os valores culturais japoneses mais significativos, ou seja, a hierarquia, a ética dos débitos, a vergonha, a responsabilidade, a autodisciplina e a competição, conforme citados por Camacho. Mas a autora mostra também que o modo como esses valores - embora nomeados com terminologia semelhante - são efetivados no cotidiano difere bastante de uma cultura para outra.

1. A expressão consta da tese de doutorado de Zeila de Brito Fabri Demartini, “Observações sociológicas sobre um tema controverso: população rural e educação em São Paulo”. Faculdade de Filosofia, Letras e Ciências Humanas, Universidade de São Paulo, São Paulo, 1979.
A minha permanência no Japão também corroborou o que já pressentia: as duas culturas são praticamente opostas! 0 que é bem aceito aqui, não o é no Japão, e vice-versa. Tanto é que os meus amigos, nos seis anos que lá fiquei, foram ou americanos ou sul-americanos, mas dificilmente um japonês, pela dificuldade de diálogo, passado o período inicial do encontro.

Assim, dentro dessas diferenças, se considerarmos o papel da brincadeira no currículo escolar, o que faz Kishimoto, no capítulo "Acelerar o ensino ou preservar o brincar: experiência de dois países", veremos que o Japão, embora conservador e disciplinador na educação, preserva o espírito de brincar como parte da cultura infantil. O Brasil, embora adotando o paradigma de criança cidadã, com direito ao brincar, vive o conflito entre as intenções e as ações. $\mathrm{Na}$ verdade, a visão cotidiana que se tem do povo japonês carece de estudos, afirma Kobayashi, e esse desconhecimento atinge os próprios membros da comunidade nipo-brasileira.

Quanto ao ensino da língua japonesa - tema dos capítulos 8 e 9 -, sabe-se que as primeiras escolas de língua japonesa (as nihongo gakko) nasceram no seio das comunidades japonesas, ligadas ou não às associações administrativas locais, de forma concentrada no 
estado de São Paulo, conforme Ota nos conta, em "O ensino de língua japonesa no Brasil: enfoque nos cursos de Ensino Fundamental, Médio e Superior". Nas últimas décadas, porém, com a chegada dos próprios imigrantes e de seus descendentes à região urbana, deixando a comunidade rural, somada ao fenômeno decasségui, houve mudanças no quadro do ensino dessa língua. Somente em 1962, continua a autora, foi implantado o curso de Língua e Literatura Japonesa na Universidade de São Paulo. Já os cursos de língua japonesa nos Centros de Línguas da Secretaria da Educação dos estados de São Paulo e do Paraná foram implantados em 1989, diz Ota.

0 ensino de língua japonesa no Brasil - ensina-nos o capítulo de Morales, "As escolas comunitárias nihongogakkô: ontem e hoje" -, caracteriza-se atualmente pela diversidade, impulsionado por diferentes tipos de alunos. Vale destacar, continua a autora, que, enquanto no período pré-guerra as escolas eram normalmente administradas por Associação de Pais e/ou Japoneses, no Pós-Guerra, surgiram cursos de professores autônomos, alguns originários do sistema das escolas comunitárias. Em 1980, no esteio do aquecimento das relações bilaterais, o japonês era estudado por muitos descendentes, visando ao ingresso em empresas japonesas sediadas no Brasil. Ainda na década de 1980, a JICA e a Fundação Japão canalizaram recursos para investir na formação continuada de professores de língua japonesa, concedendo bolsas integrais, com estudos realizados no Japão.

O livro encerra-se com questões ligadas ao movimento decasségui e à situação escolar das crianças no Brasil e no Japão. Assim, segundo Costa relata, em "Movimento decasségui e a situação escolar das crianças no Brasil e no Japão", passados aproximadamente 80 anos, o fluxo de imigrantes se inverte: nipo-brasileiros buscam melhores condições de vida nas linhas de fábricas japonesas, em serviços pouco qualificados. Porém, o que poderia ser uma oportunidade de aprendizagem cultural para os nipo-brasileiros - como vivenciar a cultura de seus antepassados para compreender melhor sua identidade e o papel na sociedade brasileira - não vem ocorrendo, segundo a autora.

Por outro lado, a estrutura familiar dos nipo-brasileiros tem sofrido vários desafios: ausências dos pais, conflitos de identidade no Japão e no Brasil, rupturas familiares, tais como, abandono, traições, divórcios. Nesse contexto, a escola toma a maior parte da responsabilidade pela educação das crianças, já que eles ficam em período integral nas diversas instituições brasileiras e japo- 
nesas, ainda segundo o relato de Costa.

Para as crianças e os jovens que vivem ou viveram por longos anos no Japão, o retorno ao Brasil é difícil e delicado, em especial no que tange à proficiência da língua portuguesa. Mesmo aqueles que frequentaram as escolas brasileiras no Japão enfrentam problemas de adaptação nas escolas do Brasil, em relação não só aos costumes, mas também ao acompanhamento das aulas, segundo o que nos conta Ishikawa, em "Condições das crianças e jovens brasileiros no Japão e suas perspectivas". Nesse particular, vejo muita semelhança na questão linguística, com a situação que aconteceu em casa, no relacionamento com meus pais. Eles tinham dificuldade na língua portuguesa e nós, na japonesa. Eram poucas as situações de diálogo, principalmente com meu pai. Sei que hoje esse fenômeno se repete, pelo lado oposto.

Educação e Cultura: Brasil e Japão é um livro que merece ser lido tanto por ancestrais issei ou nissei como pe- las novas gerações de nipo-brasileiros e, com certeza, por pessoas de outras nacionalidades que convivem conosco. A reunião de onze artigos, fundamentados por pesquisa e bibliografia pertinente e atual e escritos por cientistas de importantes universidades nacionais e estrangeiras, é uma preciosa coletânea que nos faz entender, por meio de minuciosa explicação, o significado da relação Brasil-Japão, proporcionado pelo imigrante japonês; e hoje, inversamente, pelo imigrante nipo-brasileiro em terras japonesas.

Mesmo aqueles que possam ter vivenciado os anos de 1930, 40 ou 50, como é o meu caso, talvez não tenham a dimensão do que esse fenômeno da imigração japonesa representou e continua representando em suas vidas, nos relacionamentos com familiares ou amigos. O livro é, assim, uma porta aberta para que - pelas reflexões feitas por seus autores - repensemos nosso passado para, desse modo, compreender as situações que nos cercam no presente. 